\title{
HLA sensitization in ventricular assist device recipients: Does type of device make a difference?
}

\author{
Ganesh S. Kumpati, MD \\ Daniel J. Cook, PhD \\ Eugene $\mathrm{H}$. Blackstone, $\mathrm{MD}^{\mathrm{a}, \mathrm{c}}$ \\ Jeevanantham Rajeswaran, $\mathrm{MSc}^{\mathrm{C}}$ \\ Ashraf S. Abdo, MBBS ${ }^{b}$ \\ James B. Young, $M D^{d}$ \\ Randall C. Starling, MD, MPH \\ Nicholas G. Smedira, MD \\ Patrick M. McCarthy, MDa
}

From the Department of Thoracic and Cardiovascular Surgery, ${ }^{\mathrm{a}}$ Allogen Laboratory, ${ }^{\mathrm{b}}$ Department of Biostatistics and Epidemiology, ${ }^{\mathrm{c}}$ and Department of Cardiovascular Medicine, ${ }^{\mathrm{d}}$ The Cleveland Clinic Foundation, Cleveland, Ohio.

Presented at the Twenty-first Annual Meeting of the International Society for Heart and Lung Transplantation, Vancouver, Canada, April 25-29, 2001, and the Transplant 2001 Meeting (joint meeting of the American Society of Transplantation/ American Society of Transplant Surgeons), Chicago, Ill, May 12-16, 2001

Received for publication July 23, 2003; revisions requested Dec 2, 2003; revisions received Jan 21, 2004; accepted for publication Jan 27, 2004

Address for reprints: Patrick M. McCarthy, MD, The Cleveland Clinic Foundation, 9500 Euclid Ave, Desk F25, Cleveland, OH 44195 (E-mail: mccartp@ccf.org).

J Thorac Cardiovasc Surg 2004;127:1800-7

$0022-5223 / \$ 30.00$

Copyright $\odot 2004$ by The American Association for Thoracic Surgery

doi:10.1016/j.jtcvs.2004.01.014
Background: We sought to (1) characterize the temporal pattern of T-cell panel reactive antibody during ventricular assist device support, (2) identify predictors of higher T-cell panel reactive antibody during ventricular assist device support, and (3) determine whether device type remained a predictor after accounting for nonrandom device selection.

Methods: Between December 1991 and August 2000, 239 patients received implantable ventricular assist devices, of whom 231 had T-cell panel reactive antibody measured. Panel reactive antibody was measured before implantation of the assist device, approximately 2 weeks after device implantation, irregularly thereafter depending on clinical events and length of support, and at transplantation. Longitudinal mixed modeling was used to characterize the temporal pattern of sensitization and its predictors during ventricular assist device support. To account for nonrandom factors in device selection when comparing HeartMate (Thermo Cardiosystems, Inc, Woburn, Mass) and Novacor (Baxter Healthcare Corp, Novacor Div, Oakland, Calif) devices, we propensity-matched patients according to baseline characteristics.

Results: T-cell panel reactive antibody increased rapidly after implantation of the ventricular assist device and then immediately began to decrease. Predictors of higher T-cell panel reactive antibody during support with the assist device were a shorter interval from device implantation to T-cell panel reactive antibody measurement $(P<.0001)$, female sex $(P=.0004)$, younger age $(P=.01)$, higher T-cell panel reactive antibody before device implantation $(P=.03)$, more perioperative red blood cell transfusions $(P=.006)$, and an earlier date of device implantation $(P$ $=.001)$. In matched patients, device type was not a predictor of higher T-cell panel reactive antibody during ventricular assist device support $(P=.8)$.

Conclusions: HLA sensitization during ventricular assist device support is not constant but increases rapidly at implantation and then decreases. This temporal pattern of sensitization is influenced by patient factors and not by the type of device.

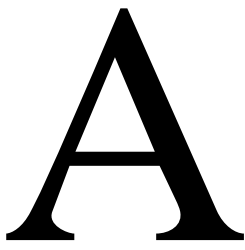

ntibodies to class I human leukocyte antigens (HLA sensitization) in heart transplant recipients are associated with graft rejection and decreased transplant survival. ${ }^{1}$ Studies of immunologic changes in patients requiring an implantable ventricular assist device (VAD) who received the HeartMate device (Thermo Cardiosystems, Inc, Woburn, Mass) suggest that excessive antibody production during VAD support may be related to the VAD blood-contacting 
TABLE 1. Devices used, by type and year

\begin{tabular}{|c|c|c|c|c|c|c|c|c|c|c|}
\hline \multirow[b]{2}{*}{ Device } & \multicolumn{9}{|c|}{ Year of VAD placement } & \multirow[b]{2}{*}{ Total } \\
\hline & $1992^{*}$ & 1993 & 1994 & 1995 & 1996 & 1997 & 1998 & 1999 & $2000 t$ & \\
\hline HeartMate & 9 & 15 & 13 & 32 & 30 & 3 & 9 & 43 & 12 & 166 \\
\hline Novacor & 0 & 0 & 0 & 0 & 2 & 35 & 17 & 1 & 0 & 55 \\
\hline Thoratec & 0 & 0 & 0 & 0 & 0 & 0 & 5 & 1 & 4 & 10 \\
\hline Total & 9 & 15 & 13 & 32 & 32 & 38 & 31 & 45 & 16 & 231 \\
\hline
\end{tabular}

$V A D$, Ventricular assist device.

*Includes December 1991.

tUp to August 2000.

surface via direct modulation of lymphocyte function by biomaterial. ${ }^{2-4}$ In this context, it is not clear whether there are differences among currently available devices (and their different biomaterials) in contributing to HLA sensitization. Other studies of HLA sensitization during VAD support suggest that transfusions and sensitization before device implantation (especially in women) are important risk factors. ${ }^{5,6}$ At our institution, we have had substantial experience with both HeartMate and Novacor (Baxter Healthcare Corp, Novacor Div, Oakland, Calif) implantable VADs.

The purposes of this study were to (1) characterize the temporal pattern of T-cell panel reactive antibody (TPRA) during VAD support, (2) identify predictors of higher TPRA during VAD support, and (3) determine whether device type remained a predictor after accounting for nonrandom device selection.

\section{Methods}

\section{Patients}

Between December 1991 and August 2000, 239 patients received implantable VADs at The Cleveland Clinic Foundation as a bridge to transplantation $(n=236)$ or as permanent therapy $(n=3)$. Patients were included regardless of pretransplantation management. Thirty patients (13\%) received plasmapheresis and mycophenolate mofetil before transplantation. None received cyclophosphamide or intravenous immunoglobulin. Patients without sensitization data $(\mathrm{n}=5)$ and individual recipients who had multiple device types used $(n=3)$ were not included in this study, leaving 231 patients. Of these, $37(16 \%)$ were female, and 141 $(61 \%)$ had ischemic cardiomyopathy as the cause of end-stage heart failure. The duration of VAD support ranged from 0 to 1043 days, with 18,200 cumulative patient-days of support.

Device types used (Table 1) included HeartMate only $(\mathrm{n}=$ 166), Novacor only $(n=55)$, and Thoratec (Thoratec Corporation, Pleasanton, Calif) only $(\mathrm{n}=10: 4$ recipients with isolated left VADs, 1 with an isolated right $\mathrm{VAD}$, and 5 with biventricular VADs). Of the 231 patients, 154 received a heart transplant, 3 were explanted for recovery, 68 died on support, and 6 were on VAD support as of the study closure date.

\section{Measurement of HLA Sensitization}

Recipients' sera were heat-treated to remove immunoglobulin M reactivity and were tested by complement-dependent lymphocyto- toxicity against a comprehensive 25- to 50-member cell panel of HLA-typed donors selected to represent most of the defined HLA specificities. Using cytotoxicity by standard dye-exclusion assay, positive reactions were expressed quantitatively as a percentage of the total T-cell panel.

TPRA was measured before VAD implantation (median, 3 days; 10th percentile, 1 day; 90th percentile, 82 days), approximately 2 weeks after VAD implantation, irregularly thereafter depending on clinical events and length of support, and at transplantation. A total of 593 TPRA measurements were obtained for the 231 patients: $224(97 \%)$ had a TPRA measurement before VAD implantation, 106 (54\% of those alive at 2 weeks) had a measurement approximately 2 weeks after VAD implantation, and 150 (97\% of those who underwent transplantation) had a measurement at transplantation; the remaining measurements were performed between approximately 2 weeks and transplantation. Autoantibodies were found in 2 patients $(0.9 \%)$.

\section{Data Analysis}

The end point for this study was TPRA level during VAD support. The analytic strategy was as follows: (1) determine the temporal pattern of TPRA change during VAD support; (2) identify modulators of the pattern, particularly the effect of VAD type; and (3) verify the presence or absence of an effect of VAD type by accounting for nonrandom device selection.

\section{Specific Methods}

The temporal pattern of TPRA levels during VAD support was characterized by using longitudinal mixed modeling (PROC MIXED; SAS Inc, Cary, NC) to account for (1) the variable intervals of TPRA measurements during VAD support and (2) repeated (serial) measurements in each patient. ${ }^{7}$ Because of the limited provision within the software for exploring multivariable relations, we screened variables by using ordinary multivariable linear regression (which assumes independence of observations) to identify candidates for mixed-model investigation; these candidates and transformations of continuous and ordinal variables were entered simultaneously into the mixed model and were then eliminated sequentially until all variables remaining had a $P$ value of .1 or less. Nearly all TPRA measurements were obtained within the first 7 months of VAD support; therefore, values in "naturally selected" patients who required prolonged VAD support obtained beyond 7 months (15 of 593 measurements) were not analyzed. 


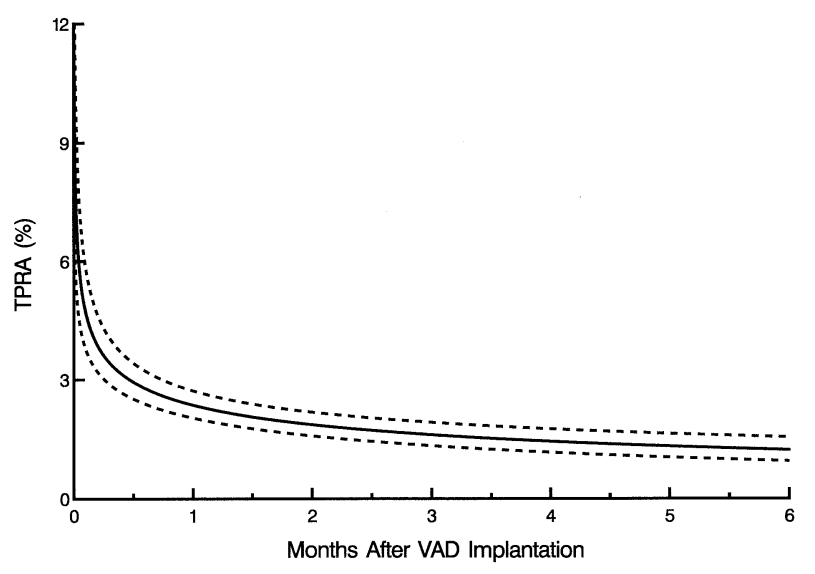

Figure 1. Mean TPRA after VAD implantation versus time after VAD implantation. Solid line is the mean curve generated by longitudinal data analysis, and dashed lines are confidence limits equivalent to $1 \mathrm{SE}(68 \%)$.

Modulators of the temporal pattern of TPRA change, and particularly of the type of device, were identified by using the model for the TPRA pattern combined with the variables listed in Appendix 1. Specifically, this required examining the interactions of each variable with the time of TPRA measurement. In screening variables, we found that plasmapheresis had been used exclusively in patients with high TPRA. Therefore, we did not use it in the analysis.

To account for nonrandom factors in device selection when comparing HeartMate and Novacor devices, we propensitymatched patients according to baseline characteristics (Appendix 2) and compared TPRA patterns. ${ }^{8,9}$

\section{Presentation}

Descriptive statistics are summarized as mean and SD for continuous variables when they were approximately normally distributed and as median, 25th, and 75th percentile and range when they were not. Categorical variables are expressed in frequencies and percentages.

Nomograms from the analyses are presented in which values for specific variables, such as age and TPRA before VAD implantation, were entered into the regression equations and the equations solved. The results are presented graphically with confidence limits equivalent to $1 \mathrm{SE}(68 \%)$.

\section{Results}

\section{Temporal Pattern of HLA Sensitization During VAD Support}

TPRA during VAD support increased immediately after VAD implantation and then rapidly began to decrease $(P<$ .0001) to levels generally lower than before placement (Figure 1). Mean TPRA before VAD implantation was 4.0\%. Mean TPRA at 1 day, 2 weeks, 1 month, 3 months, 5 months, and 7 months after VAD implantation was $6.4 \%$, $3.0 \%, 2.4 \%, 1.6 \%, 1.3 \%$, and $1.2 \%$, respectively.
TABLE 2. Predictors of higher TPRA measurements during VAD support

\begin{tabular}{|c|c|c|}
\hline Risk factor & Coefficient \pm SE & $P$ value \\
\hline Women & $1.14 \pm 0.28$ & $<.0001$ \\
\hline Younger age* & $1.5 \pm 0.44$ & .0008 \\
\hline $\begin{array}{l}\text { Shorter interval from VAD } \\
\text { implantation to TPRA } \\
\text { measurement } †\end{array}$ & $-0.70 \pm 0.17$ & $<.0001$ \\
\hline $\begin{array}{l}\text { Interaction between age and } \\
\text { interval from VAD } \\
\text { implantation to TPRA } \\
\text { measurement } \ddagger\end{array}$ & $0.46 \pm 0.15$ & .003 \\
\hline $\begin{array}{l}\text { Higher TPRA before VAD } \\
\text { implantation }\end{array}$ & $0.022 \pm 0.010$ & .03 \\
\hline $\begin{array}{l}\text { More perioperative red } \\
\text { blood cell transfusions§ }\end{array}$ & $0.37 \pm 0.13$ & .004 \\
\hline $\begin{array}{l}\text { Earlier date of VAD } \\
\text { implantation } \|\end{array}$ & $-0.016 \pm 0.0045$ & .0006 \\
\hline Novacorn & $0.093 \pm 0.22$ & .7 \\
\hline Thoratec & $0.088 \pm 0.58$ & .9 \\
\hline
\end{tabular}

TPRA, T-cell panel reactive antibody; $V A D$, ventricular assist device. *[50/age (y)] inverse transformation.

†Ln[interval to TPRA measurement (years)] logarithmic transformation. $\ddagger$ As age decreases, the influence of shorter interval becomes smaller. $\S$ Ln(perioperative red blood cell transfusions) logarithmic transformation. \|(Date of VAD implantation $)^{2}$ squared transformation.

१Versus HeartMate.

\section{Modulators of TPRA During VAD Support}

Modulators of the temporal pattern of TPRA during VAD support were female sex $(P=.0004)$, younger age $(P=$ $.01)$, higher TPRA before VAD implantation $(P=.03)$, more perioperative red blood cell transfusions $(P=.006)$, and earlier date of VAD implantation $(P=.001$; Table 2$)$. It is important to note that device type (HeartMate vs Novacor vs Thoratec) was not identified as a modulator of TPRA level $(P>.7)$, nor were baseline characteristics related to severity of illness.

The strong effect of female sex on TPRA is demonstrated in Figure 2. The effect of younger age on higher TPRA 2 weeks after VAD implantation is illustrated in Figure 3. The modest relationship of TPRA level before and 2 weeks after VAD implantation is illustrated in Figure 4. The strong effect of increasing the number of perioperative units of red blood cell transfusions on TPRA 2 weeks after VAD implantation is illustrated in Figure 5.

\section{Matched Comparison of Device Types}

Patients who received HeartMate and Novacor devices differed in age, creatinine level, bilirubin level, and TPRA before VAD implantation (Table 3). After propensity matching, the resulting pairs were well matched (Table 4). In matched patients, device type was not a predictor of higher TPRA level during VAD support $(P=.8$; Table 5). 


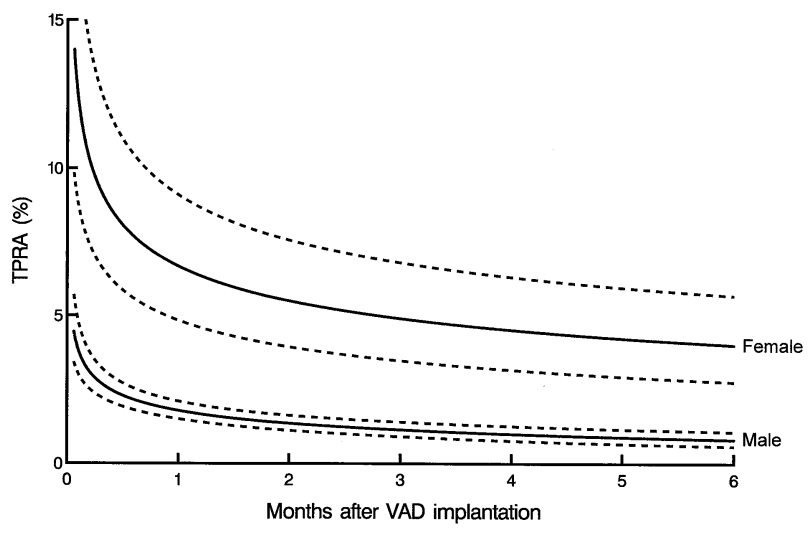

Figure 2. Risk-adjusted relation of TPRA after VAD implantation and time by sex. This is a nomogram of Table 2, in which age = 55 years (median age), TPRA before VAD implantation $=0$, perioperative red blood cell transfusions $=12$ units (median), and date of VAD implantation $=1997$.

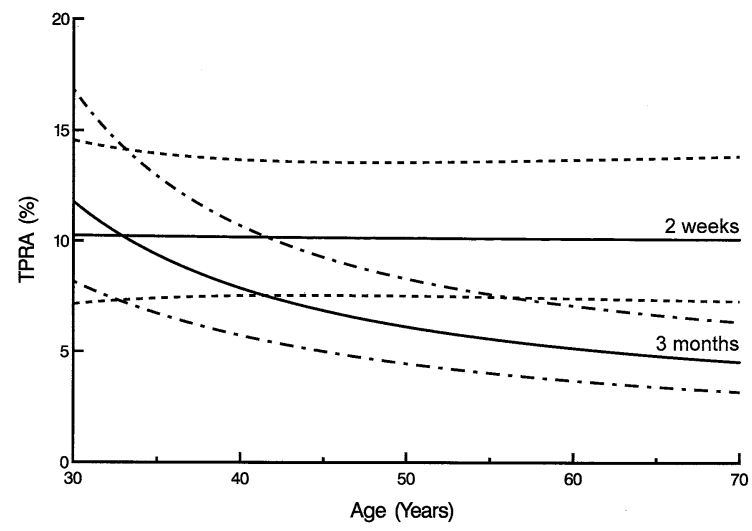

Figure 3. Risk-adjusted relation of TPRA and age 2 weeks and 3 months after VAD implantation. This nomogram of Table 2 is for a woman; TPRA before VAD implantation $=0$, perioperative red blood cell transfusions $=12$ units (the median), and date of VAD implantation $=1997$ (the median date).

\section{Discussion}

\section{TPRA Measurement}

Traditionally, TPRA results are expressed as greater than or less than $10 \%$ positive reactions. In this study, to use all available information, we analyzed TPRA as a continuous value from $0 \%$ to $100 \%$. The relations found with this analytic technique support this approach. In addition, because TPRA measurements are not continuously monitored but are made at different times for different patients, and at variable times for an individual patient, determining the time after VAD implantation at which a patient's TPRA exceeds $10 \%$ is not possible with any degree of accuracy.

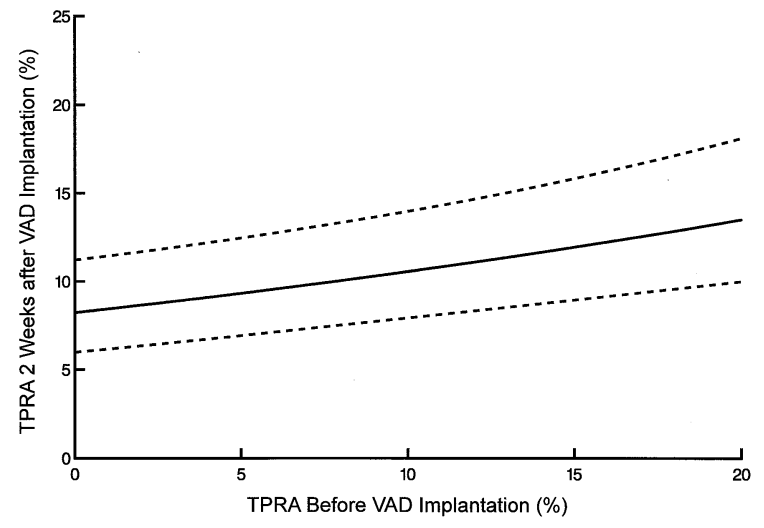

Figure 4. Risk-adjusted relation of TPRA before and 2 weeks after VAD implantation. This nomogram of Table 2 is for a woman, age $=55$ years (median), perioperative red blood cell transfusions $=$ 12 units, and date of VAD implantation $=1997$.

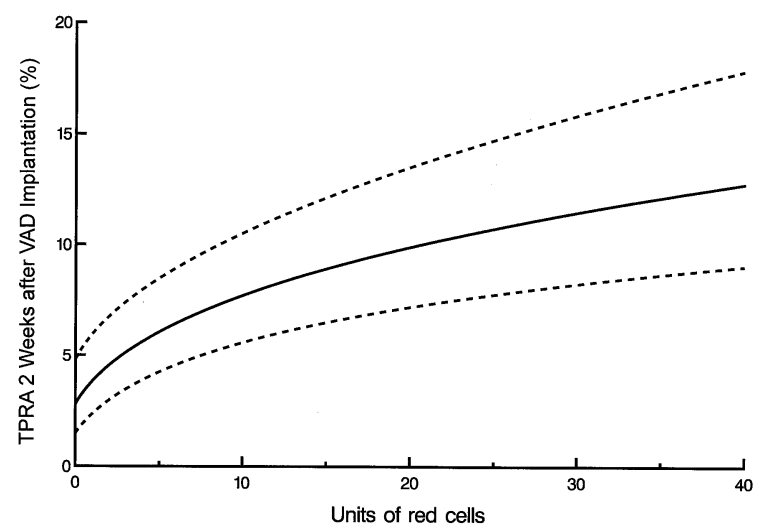

Figure 5. Risk-adjusted relation of TPRA 2 weeks after VAD implantation and number of perioperative red blood cell transfusions. This is a nomogram of Table 2 for a woman; age $=55$ years (median), TPRA before VAD implantation $=0$, and date of VAD implantation $=1997$.

\section{Principal Findings}

Temporal pattern of sensitization. The temporal patterns of TPRA change during VAD support consisted of a rapid increase followed by a rapid progressive decrease. This pattern suggests greater effects of early postoperative events rather than a continued effect of VAD support. This may be explained by any or all of the following: (1) HLA in transfusions administered early after surgery; (2) initial interaction between blood and the device surface (contact activation), ameliorated rapidly by passivation of the surface by serum proteins deposited on $i^{10-12}$; (3) longer-term remodeling of the device blood-contacting surface by pseudointima formation, making it less immunogenic with longer device support; and (4) alteration of the systemic 
TABLE 3. Characteristics of unmatched HeartMate and Novacor recipients

\begin{tabular}{|c|c|c|c|}
\hline Characteristic & HeartMate $(n=166)$ & Novacor $(n=55)$ & $P$ value \\
\hline \multicolumn{4}{|l|}{ Demographics } \\
\hline Age (mean years $\pm S D$ ) & $55 \pm 10$ & $52 \pm 12$ & .1 \\
\hline Women (\%) & $24(14)$ & $7(13)$ & .7 \\
\hline \multicolumn{4}{|l|}{ Clinical history } \\
\hline Bilirubin, median $(01,03)$ & $1.4(0.9,2.6)$ & $1.6(1.3,2.3)$ & .01 \\
\hline Creatinine, median $(01,03)$ & $1.5(1.1,2.1)$ & $1.5(1.3,2.1)$ & .07 \\
\hline Pre-VAD TPRA, median $(01,03)$ & $0(0,4)$ & $0(0,1.5)$ & .6 \\
\hline Intubation $(\%)$ & $102(61)$ & $32(58)$ & .6 \\
\hline IABP $(\%)$ & $127(77)$ & $45(81)$ & .4 \\
\hline Previous cardiac surgery $(\%)$ & $84(51)$ & $28(51)$ & .9 \\
\hline Idiopathic etiology $(\%)$ & $46(28)$ & $18(33)$ & .5 \\
\hline Ischemic etiology $(\%)$ & $102(61)$ & $35(63)$ & .7 \\
\hline ECMO $(\%)$ & $38(23)$ & $8(15)$ & .18 \\
\hline
\end{tabular}

Q1, 25th percentile; 03, 75th percentile; TPRA, T-cell panel reactive antibody; IABP, intra-aortic balloon pump; ECMO, extracorporeal membrane oxygenation; $V A D$, ventricular assist device.

TABLE 4. Characteristics of matched HeartMate and Novacor recipients

\begin{tabular}{|c|c|c|c|}
\hline Characteristic & HeartMate $(n=50)$ & Novacor $(n=50)$ & $P$ value \\
\hline \multicolumn{4}{|l|}{ Demographics } \\
\hline Age (mean years $\pm S D$ ) & $53 \pm 12$ & $54 \pm 10$ & 6 \\
\hline Women (\%) & $6(12)$ & $5(10)$ & .7 \\
\hline \multicolumn{4}{|l|}{ Clinical history } \\
\hline Bilirubin, median $(01,03)$ & $1.6(1.1,2.6)$ & $1.6(1.2,2.5)$ & .9 \\
\hline Creatinine, median $(01,03)$ & $1.6(1.2,2.4)$ & $1.5(1.3,2.0)$ & .7 \\
\hline Pre-VAD TPRA, median $(01,03)$ & $0(0,0)$ & $0(0,1)$ & .7 \\
\hline Intubation $(\%)$ & $34(68)$ & $30(60)$ & .4 \\
\hline $\operatorname{IABP}(\%)$ & $42(84)$ & $41(82)$ & .8 \\
\hline Previous cardiac surgery $(\%)$ & $27(54)$ & $26(52)$ & .8 \\
\hline Idiopathic etiology $(\%)$ & $13(26)$ & $15(30)$ & 6 \\
\hline Ischemic etiology $(\%)$ & $35(70)$ & $33(66)$ & .7 \\
\hline ECMO $(\%)$ & $10(20)$ & $8(16)$ & .6 \\
\hline
\end{tabular}

Q1, 25th percentile; 03, 75th percentile; TPRA, T-cell panel reactive antibody; IABP, intra-aortic balloon pump; ECMO, extracorporeal membrane oxygenation; $V A D$, ventricular assist device.

inflammatory milieu. The latter may occur with resolution of preoperative shock.

Predictors of sensitization. Predictors of higher TPRA level during VAD support underscore the importance of the patient profile and events during support. Consistent with previous reports, we found women to be at higher risk. ${ }^{5}$ Although data were not available on the number of previous pregnancies, past heart transplant investigations have found increased risk associated with being a woman was a surrogate for previous pregnancies. ${ }^{13}$ Younger age suggests that enhanced immune responsiveness is a component of sensitization. Total red blood cell transfusions were an important predictor of higher TPRA, which is also consistent with the report of Massad and colleagues. ${ }^{5}$ This might be related to the HLA found on leukocytes within the transfusions and to associated events, such as shock. Although the leukocytereduced fraction of red blood cell transfusions was not associated with decreased sensitization, we have used leu- kocyte-reduced products since 1995 on the basis of earlier studies that showed the benefits of this strategy. ${ }^{14}$ Platelet transfusions have been found in earlier studies to be predictors of sensitization, especially non-leukocyte-reduced platelets, ${ }^{5,6,14}$ but we did not observe this. We attribute much of the decrease in sensitization over the experience to changes in blood transfusion methods (such as use of leukocyte-depleted products) and to the use of blood-sparing techniques (such as the routine use of aprotinin and vitamin $\mathrm{K})$. The role of pretransplantation plasmapheresis could not be determined in this study because only highly sensitized patients received this treatment.

Role of device. In this study, device type (HeartMate vs Novacor vs Thoratec) was not a predictor of sensitization either in the initial analysis or in propensity-matched pairs of HeartMate and Novacor patients. Decisions regarding device type were related to device properties (reliability and thromboembolism) and not to the potential for sensitization. 
Previous studies of device/immune system interactions have focused on interactions with HeartMate devices. Initial implantation is associated with activation of complement and coagulation factors, and this contributes to bleeding after implantation. ${ }^{15-18}$ However, the textured surface of the HeartMate device allows formation of a pseudointima after implantation. ${ }^{19,20}$ At explantation, the pseudointima contains macrophages and T cells. ${ }^{21,22}$ Previous studies using an in vitro model containing VAD pseudointima and biomaterial have found T-cell activation with subsequent apoptosis and B-cell activation. ${ }^{3}$ This phenomenon has recently been shown to peak shortly after VAD implantation and to decrease over time in patients receiving a DeBakey VAD (MicroMed Technologies, Inc, Houston, Tex). ${ }^{23}$

In combination, the pattern and predictors of sensitization suggest that the relevant influences are sensitization before VAD placement (multiparous women and previous transfusions), immune responsiveness (age), and amount of HLA exposure (transfusions). Our findings suggest that device biomaterial/immune system interactions are transient, not constant, and they occur contemporaneously with other influences. The differences in the HeartMate and Novacor devices, including their respective biomaterials, have not resulted in detectable differences in HLA sensitization between the 2 .

\section{Future Horizons}

Newer, smaller VADs (eg, axial flow devices) may offer easier implantation with less perioperative bleeding, resulting in fewer perioperative transfusions and a smaller surface area for immunologic exposure. Immunosuppression begun early after VAD implantation may be effective in decreasing antibody production.

\section{Limitations}

This was an observational study encompassing the entire VAD experience at our institution. Selection of device type changed nonsystematically over time. After the 2-week time point, TPRA data were obtained at variable intervals influenced by clinical events and length of device support. Although our analysis accounted for this variation, it did not account for so-called informative censoring-in this case, depletion of the study group by nonrandom selection of patients for transplantation. Finally, the patient population is a complex, heterogeneous group, and there have been many incremental practice changes over time. Some of these factors, including preferential use of plasmapheresis in highly sensitized patients, are surely not accounted for and could individually correlate with the end points of HLA sensitization (confounding).

\section{Conclusions}

The pattern and predictors of sensitization suggest that the relevant influences are sensitization before VAD implanta-
TABLE 5. Predictors of higher TPRA measurements during VAD support in matched HeartMate and Novacor recipients

\begin{tabular}{lcc}
\hline Risk factor & Coefficient \pm SE & $P$ value \\
\hline Women & $1.6 \pm 0.41$ & .0002 \\
Younger age* & $1.5 \pm 0.45$ & .001 \\
Higher pre-VAD TPRA & $0.15 \pm 0.043$ & .001 \\
$\begin{array}{l}\text { More perioperative red } \\
\quad \text { blood cell transfusions }\end{array}$ & $0.27 \pm 0.14$ & .07 \\
$\begin{array}{l}\text { Earlier date of VAD } \\
\quad \text { implantationł }\end{array}$ & $-0.015 \pm 0.0074$ & .05 \\
$\begin{array}{l}\text { Shorter interval from VAD } \\
\quad \text { implantation to TPRA }\end{array}$ & $-0.29 \pm 0.085$ & .001 \\
$\quad$ measurement§ & & \\
HeartMate VAD & & .8
\end{tabular}

TPRA, T-cell panel reactive antibody; $V A D$, ventricular assist device. *[50/age (y)] inverse transformation.

tLn(perioperative red blood cell transfusions) logarithmic transformation. $\ddagger$ (Date of VAD implantation) $)^{2}$ squared transformation.

$\S L n$ (interval to TPRA measurement) logarithmic transformation.

tion (multiparous women and previous transfusions), immune responsiveness (age), amount of HLA exposure (transfusions), and initial interaction between blood and the contact surface. Our findings suggest that device biomaterial/immune system interactions may not be constant and occur in combination with other influences. The potential differences in the devices (and their respective biomaterials) have not resulted in detectable differences in HLA sensitization between HeartMate and Novacor devices.

\section{References}

1. Bishay ES, Cook DJ, Starling RC, Ratliff NB Jr, White J, Blackstone $\mathrm{EH}$, et al. The clinical significance of flow cytometry crossmatching in heart transplantation. Eur J Cardiothorac Surg. 2000;17:362-9.

2. Ankersmit HJ, Tugulea S, Spanier T, Weinberg AD, Artrip JH, Burke EM, et al. Activation-induced T-cell death and immune dysfunction after implantation of left-ventricular assist device. Lancet. 1999;354: 550-5.

3. Itescu S, Ankersmit JH, Kocher AA, Schuster MD. Immunology of left ventricular assist devices. Prog Cardiovasc Dis. 2000;43:67-80.

4. Schuster M, Kocher A, Lietz K, Ankersmit J, John R, Edwards N, et al. Induction of CD40 ligand expression in human T cells by biomaterials derived from left ventricular assist device surface. Transplant Proc. 2001;33:1960-1.

5. Massad MG, Cook DJ, Schmitt SK, Smedira NG, McCarthy JF, Vargo RL, et al. Factors influencing HLA sensitization in implantable LVAD recipients. Ann Thorac Surg. 1997;64:1120-5.

6. Moazami N, Itescu S, Williams MR, Argenziano M, Weinberg A, Oz MC. Platelet transfusions are associated with the development of anti-major histocompatibility complex class I antibodies in patients with left ventricular assist support. J Heart Lung Transplant. 1998;17: 876-80.

7. Diggle PJ, Heagerty PJ, Liang KY, Zeger SL. Analysis of longitudinal data. 2nd ed. New York: Oxford University Press; 2002.

8. Rubin DB. Estimating causal effects from large data sets using propensity scores. Ann Intern Med. 1997;127:757-63.

9. Blackstone EH. Comparing apples and oranges. J Thorac Cardiovasc Surg. 2002;123:8-15.

10. Addonizio VP Jr, Macarak J, Nicolaou KC, Edmunds LH Jr, Colman 
RW. Effects of prostacyclin and albumin on platelet loss during in vitro simulation of extracorporeal circulation. Blood. 1979;53:103342.

11. Packham MA, Evans G, Glynn MF, Mustard JF. The effect of plasma proteins on the interaction of platelets with glass surfaces. J Lab Clin Med. 1969;73:686-97.

12. Salzman EW, Merrill EW, Binder A, Wolf CF, Ashford TP, Austen WG. Protein-platelet interaction on heparinized surfaces. J Biomed Mater Res. 1969;3:69-81.

13. Johnson MR, Naftel DC, Hobbs RE, Kobashigawa JA, Pitts DE, Levine TB, et al. The incremental risk of female sex in heart transplantation: a multiinstitutional study of peripartum cardiomyopathy and pregnancy. Cardiac Transplant Research Database Group. J Heart Lung Transplant. 1997;16:801-12.

14. van Marwijk Kooy M, van Prooijen HC, Moes M, Bosma-Stants I, Akkerman JW. Use of leukocyte-depleted platelet concentrates for the prevention of refractoriness and primary HLA alloimmunization: a prospective, randomized trial. Blood. 1991;77:201-5.

15. Himmelreich G, Ullmann H, Riess H, Rosch R, Loebe M, Schiessler A, et al. Pathophysiologic role of contact activation in bleeding followed by thromboembolic complications after implantation of a ventricular assist device. ASAIO J. 1995;41:M790-4.

16. Wang IW, Kottke-Marchant K, Vargo RL, McCarthy PM. Hemostatic profiles of HeartMate ventricular assist device recipients. ASAIO J. 1995;41:M782-7.

17. Livingston ER, Fisher CA, Bibidakis EJ, Pathak AS, Todd BA, Furukawa $S$, et al. Increased activation of the coagulation and fibrinolytic systems leads to hemorrhagic complications during left ventricular assist implantation. Circulation. 1996;94:II227-34.

18. Spanier T, Oz M, Levin H, Weinberg A, Stamatis K, Stern D, et al. Activation of coagulation and fibrinolytic pathways in patients with left ventricular assist devices. J Thorac Cardiovasc Surg. 1996;112: 1090-7.

19. Rose EA, Levin HR, Oz MC, Frazier OH, Macmanus Q, Burton NA, et al. Artificial circulatory support with textured interior surfaces. A counterintuitive approach to minimizing thromboembolism. Circulation. 1994;90:II87-91.

20. Graham TR, Dasse K, Coumbe A, Salih V, Marrinan MT, Frazier OH, et al. Neo-intimal development on textured biomaterial surfaces during clinical use of an implantable left ventricular assist device. Eur J Cardiothorac Surg. 1990;4:182-90.

21. Rafii S, Oz MC, Seldomridge JA, Ferris B, Asch AS, Nachman RL, et al. Characterization of hematopoietic cells arising on the textured surface of left ventricular assist devices. Ann Thorac Surg. 1995;60: 1627-32.

22. Spanier TB, Chen JM, Oz MC, Stern DM, Rose EA, Schmidt AM. Time-dependent cellular population of textured-surface left ventricular assist devices contributes to the development of a biphasic systemic procoagulant response. J Thorac Cardiovasc Surg. 1999;118:404-13.

23. Ankersmit HJ, Wieselthaler G, Moser B, Gerlitz S, Roth G, BoltzNitulescu G, et al. Transitory immunologic response after implantation of the DeBakey VAD continuous-axial-flow pump. J Thorac Cardiovasc Surg. 2002;123:557-61.

24. Rosenbaum PR, Rubin DB. Reducing bias in observational studies using subclassification on the propensity score. J Am Stat Assoc. 1984;79:516-24.

25. Parsons LS. Reducing bias in a propensity score matched-pair sample using greedy matching techniques. In: Proceedings of the Twentysixth Annual SAS Users Group International Conference. Cary (NC): SAS Institute Inc; 2001. p. 214-26.

\section{Appendix 1. Variables used in analysis}

VAD type

Age

Sex

Cause of heart failure (ischemic, dilated, valvar, congenital, myocarditic)

Previous cardiac surgery

Preoperative creatinine

Preoperative bilirubin

Preoperative intubation

Preoperative hemodialysis

Preoperative IABP

Preoperative ECMO

Preoperative Abiomed BVS 5000 support

Pre-VAD placement TPRA

Need for any mechanical right ventricular support (ECMO,

Abiomed BVS 5000, and/or Thoratec RVAD)

Transfusions (perioperative [ \pm 1 day of VAD implantation] and total)

Red blood cells (total units, leukocyte-reduced units)

Platelets (total units, leukocyte-reduced units)

Fresh frozen plasma (total units)

Bloodstream infection (number of episodes)

$V A D$, Ventricular assist device; IABP, intra-aortic balloon pump; ECMO, extracorporeal membrane oxygenation; $R V A D$, right ventricular assist device; TPRA, T-cell panel reactive antibody.

Appendix TABLE 1. Predictors of Novacor versus HeartMate

\begin{tabular}{lcc}
\hline Predictor & Logistic coefficient \pm SE & $P$ value \\
\hline Younger age* & $0.93 \pm 0.48$ & .05 \\
Lower pre-VAD TPRA & $-0.066 \pm 0.038$ & .08 \\
Higher creatinine† & $-0.74 \pm 0.41$ & .07 \\
Higher bilirubin $\ddagger$ & $-3.4 \pm 1.1$ & .002 \\
Lower bilirubin§ & $-2.5 \pm 0.88$ & .004
\end{tabular}

$V A D$, Ventricular assist device; TPRA, T-cell panel reactive antibody. *[50/age (y)] inverse transformation.

$\dagger(1.5 /$ creatinine $)$ inverse transformation.

$\ddagger(1.4$ /bilirubin) inverse transformation.

$\S\llcorner n$ (bilirubin) logarithmic transformation.

\section{Appendix 2: Propensity-Matched Groups}

The influence of device type (HeartMate vs Novacor) on TPRA serial measurements was determined for all 221 patients and for propensity-matched pairs. In the entire group, HeartMate made up $166(75 \%)$ and Novacor $55(25 \%)$ of the devices.

As a first step toward propensity analysis, a parsimonious model was established for Novacor by using multivariable logistic 
regression. ${ }^{8}$ All pre-VAD variables were considered (Appendix Table 1) for determining factors associated with group membership (Novacor vs HeartMate). Continuous variables were initially analyzed by decile analysis; we then selected those transformations of scale that best calibrated the variable to group membership.

Having established a parsimonious model, we added all other pre-VAD variables representing patient sex and clinical history (saturated model). These included female sex, idiopathic etiology, ischemic etiology, extracorporeal membrane oxygenation, intuba- tion, intra-aortic balloon pump, and previous cardiac surgery. The $c$ statistic was 0.76 .

A propensity score was calculated for each patient by solving the saturated model for the probability of a Novacor device being implanted. ${ }^{24}$ Greedy matching using the propensity score as the sole criterion yielded 50 well-matched pairs. ${ }^{25}$ Multivariable longitudinal mixed modeling was again performed of TPRA measurements by using these 50 pairs of patients and forcing in device type.

\section{UN THE MOVE?}

Don't miss a single issue of the journal! To ensure prompt service when you change your address, please photocopy and complete the form below.

Please send your change of address notification at least six weeks before your move to ensure continued service. We regret we cannot guarantee replacement of issues missed due to late notification.

\section{JOURNAL TITLE:}

Fill in the title of the journal here.

\section{OLD ADDRESS:}

Affix the address label from a recent issue of the journal here.

\section{NEW ADDRESS:}

Clearly print your new address here.

Name

Address

City/State/ZIP

\section{COPY AND MAIL THIS FORM TO:}

Elsevier Inc.

Subscription Customer Service

6277 Sea Harbor Dr

Orlando, FL 32887
OR FAX TO:

407-363-9661

OR E-mail:

elspcs@elsevier.com
OR PHONE:

800-654-2452

Outside the U.S., call

407-345-4000 